\title{
Reglamentos de bibliotecas públicas: ideas para elaborarlos
}

\author{
Por M. Rosa López Llebot
}

Resumen: Las bibliotecas públicas se rigen por pautas internas, llámense reglamentos, normativas o normas. ¿Para qué sirve un reglamento?, ¿qué caracteriza un buen reglamento?, ¿qué debe cumplir para ser legal?, ¿qué aspectos del uso de la biblioteca se incluyen normalmente?, ¿cuáles se olvidan? Para responder a estas preguntas hemos tomado 40 reglamentos distintos, de dos ámbitos extremos, el catalán y el de EUA, y los hemos analizado. El resultado es un trabajo de síntesis pensado para ayudar a los responsables de las bibliotecas públicas a redactar reglamentos.

Palabras clave: Reglamento, Normativa, Normas, Servicios de la biblioteca pública, Políticas de la biblioteca pública.

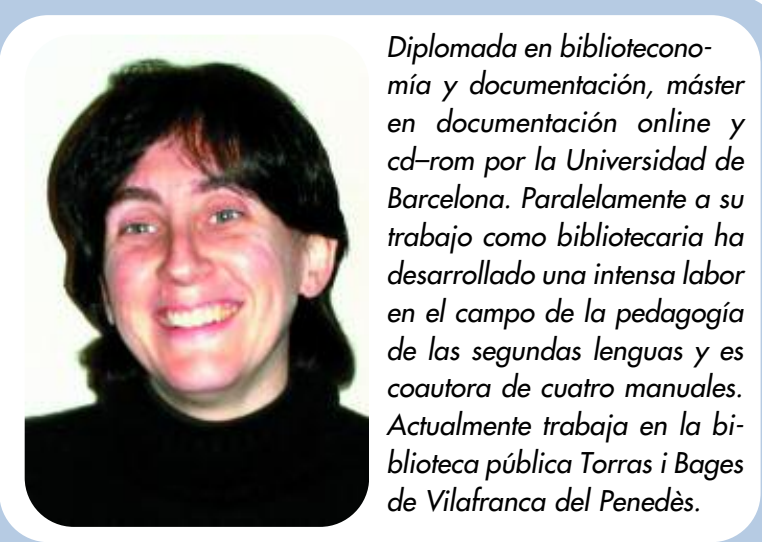

Title: The rules of public libraries: a catalogue of ideas to work up rules

Abstract: Public libraries are managed by inside standards, sometimes called rules, codes of behaviour or user guidelines. The variety of terms to mention them is only the first sign of disparity. What is the good of them?, what does characterize good rules?, what steps must fulfil rules to be legal?, which sides of the library usage are usally included?, what do they forget? To answer to these questions we have taken 40 different rules, from two extreme backgrounds, Catalonia and the United States, and we analyse them. The result is a synthesis thought to help public library managers to write rules.

Keywords: User code of behaviour, User rules, User guidelines, Public library services, Public library policies.

UN REGLAMENTO ES BASICO para el buen funcionamiento de una biblioteca pública. Su utilidad es múltiple:

- Para consensuar entre todos los miembros del personal un procedimiento de actuación y cohesionar el grupo de trabajo. Es un instrumento al que se llega para solucionar problemas planteados por el día a día.

-Para salvar situaciones incómodas con los usuarios. Últimamente se oye bastante: "yo pago mis impuestos y tengo derecho a eso o lo otro", "yo pago tu sueldo y tú trabajas para mín'. Los derechos son derechos, que no privilegios, aunque eso no sea evidente para todo el mundo. Un documento escrito y refrendado por los órganos competentes es de gran ayuda. Sin él, los responsables de las bibliotecas se encuentran en la necesidad de resolver situaciones conflictivas de manera precaria.
-Para hacer conscientes a los responsables municipales de la realidad de la biblioteca.

«Los pasos a seguir
para su disponibilidad
son diversos y todo el
proceso debe cumplir
el marco legal
establecido, ya que
de otra manera su
validez puede
cuestionarse»

Este artículo es una reflexión hecha sobre unos cuarenta reglamentos publicados: qué se dice y qué no, qué elementos formales se respetan, etc. La mayor parte de ellos son de bibliotecas públicas españolas -en concreto catalanas ${ }^{1-26}$ y una muestra más pequeña ha sido recogida de centros de $\mathrm{EUA}^{27-39}$. La elección del modelo americano puede resultar chocante, pero es útil disponer de un contrapunto, de una perspectiva ajustada a una realidad diferente. Las bibliotecas de EUA son las que quizá sufren situaciones más extremas. Algunos de los reglamentos de estas instituciones ponen los pelos de punta y la bibliografía profesional de aquel país deja constancia de los conflictos con los usuarios (delincuentes abatidos a tiros, violadores, personal de la biblioteca asediado, etc. $)^{40}$. Además, es significativa su tradición de edición web y de transparencia de las políticas de gestión, lo cual hace que este material sea muy accesible a pesar de la lejanía.

Los bibliotecarios no somos juristas pero, a pesar de todo, quizá llega un día en el que tenemos que redactar un borrador de reglamento para nuestra biblioteca, lo cual siempre nos pilla algo desprevenidos. Intentamos proveernos de otros ya realizados, los leemos con atención y asimilamos los redactados que más convienen a nuestro centro. Tampoco disponemos de 
mucho tiempo para reflexionar sobre el proceso en sí, ni mucha bibliografía especializada. Pues bien, imaginemos que ese momento ha llegado.

\section{Aspectos básicos}

Un buen reglamento se ajusta a estas características:

-Completo. Debe preverlo todo, o casi todo: derechos y deberes de los usuarios, uso de los distintos servicios y situaciones de conflicto.

-Breve. La biblioteca necesita sólo un reglamento: el código civil y el penal ya están escritos.

-Consensuado y razonado. Debe consensuarse con el personal de la biblioteca; de no ser así, éste puede no sentirlo como suyo y aplicar pautas de regulación interna paralelas.

—Renovado. Los servicios y prestaciones de la biblioteca cambian, también deben hacerlo las pautas que la rigen, a pesar de la dificultad y lentitud del proceso: redacción, aprobación por el Pleno municipal, exposición pública, publicación en boletines oficiales, etc.

-Ordenado. La información ha de aparecer bien organizada; ayudan los epígrafes claros o la estructuración jerárquica (de lo general a lo particular). El trabajo diario hace que hayamos de recurrir al reglamento en situaciones tensas, muy de vez en cuando, y es bueno no parecer perdido hojeando un pliego de papeles.

-Preciso. Debe utilizarse un lenguaje claro y concreto. A veces debemos explicar con pelos y señales cuestiones en apariencia obvias para nosotros que solemos dar por sabidas. Ahí resulta muy útil la lectura que hacen diferentes personas para detectar imprecisiones o redactados equívocos. También debe tenerse en cuenta que lo leerán los usuarios, un grupo de personas muy heterogéneo, y que su lectura debe ser fácil.

-Flexible. A pesar de nuestros esfuerzos de exhaustividad en su redacción, no es posible prever todas las contingencias. Ahí entran las cláusulas discrecionales del personal de la biblioteca o de su máximo responsable. Es una alternativa válida empleada con mesura. Al acotar los servicios de pago también es recomendable evitar mencionar tarifas concretas, de otro modo el reglamento quedará desfasado de un año para otro.

-Positivo. Es quizá la pauta más clásica que se da en la redacción de reglamentos: "evitemos decir qué no se puede hacer y centrémonos en las cosas que sí se pueden hacer". En todo caso, siempre puede resumirse y hacerlo público en forma de cartel en el que predominen las pautas positivas.

\section{Al toro}

Bien, hemos decidido redactar un reglamento para nuestra biblioteca pública. Es recomendable seguir estos pasos y consejos:

- Hay que aprovechar la experiencia de otros centros, sobre todo de los que tienen una problemática similar. Es bueno hacerse con copias de reglamentos diferentes y analizarlos apartado por apartado o, en su defecto, leer las páginas que siguen de este artículo, concretamente "partes habituales de un reglamento".

- Redactar un borrador inicial a partir de los ya conocidos y de la experiencia propia. Sobre esta base en papel pueden iniciarse sesiones de trabajo con el conjunto del personal. Es una manera de consensuarlo, darlo a conocer y completarlo, a buen seguro cuatro ojos ven más que dos, y después multiplicad por el total de compañeros.

-Elaborar un segundo borrador con las enmiendas y ampliacio- nes para, a continuación, proceder a una segunda lectura común.

- Pasar el reglamento por los trámites administrativos pertinentes.

Los pasos a seguir para su disponibilidad son varios y todo el proceso debe cumplir el marco legal establecido, ya que de otra manera su validez puede cuestionarse. La reglamentación de las condiciones de uso de las bibliotecas públicas catalanas es potestad de los municipios donde tienen la sede (art. 4.1c del Decreto 124/1999, de 4 de mayo, sobre los servicios y el personal del Sistema de Lectura Pública de Cataluña).

\section{«Un documento \\ escrito y refrendado \\ por los órganos \\ competentes es de \\ gran ayuda. Sin él, los \\ responsables de las \\ bibliotecas se \\ encuentran en la \\ necesidad de resolver \\ situaciones \\ conflictivas de \\ manera precaria»}

En Cataluña, el proceso de aprobación del reglamento de una biblioteca es idéntico al de las ordenanzas municipales y consta de las etapas que enumeramos a continuación. En otras comunidades autónomas una parte de la legislación puede diferir, pero no el marco legal estatal ni la Ley de Régimen Local (Ley 7/1985):

1. El Pleno del municipio admite a trámite la formación o modificación del reglamento (art. 61.5, Decreto 179/1995). Este paso rara vez se cumple en el caso de los reglamentos de las bibliotecas públicas.

2. Se designa una comisión de estudio encargada de redactar el texto del anteproyecto. La comisión estará formada por personal técnico 
y miembros de la corporación (art. 62, Decreto 179/1995). La realidad acostumbra a ser que los responsables de la biblioteca en solitario, o asesorados por el equipo de trabajo, redactan el borrador.

3. El Pleno del municipio aprueba inicialmente el reglamento (art. 49, Ley 7/1985, art. 178.1, Decreto legislativo 2/2003).

4. El reglamento aprobado provisionalmente entra en período de información pública y audiencia con los interesados durante 30 días (art. 49, Ley 7/1985 y art. 178.1, Decreto legislativo 2/2003). Concretamente, debe publicarse un anuncio en el boletín oficial de la provincia, en el Diario Oficial de la Generalitat de Cataluña, en uno de los medios de comunicación escrita diaria y en el tablero de anuncios de la corporación (art. 63.2, Decreto 179/1995).

5. Si no hay reclamaciones o sugerencias, el acuerdo del Pleno se hace definitivo (art. 49, Ley 7/1985 $\mathrm{y}$ art. 178.1, Decreto legislativo 2/2003).

6. El reglamento se publica en el boletín oficial de la provincia (art. 70.2, Ley 7/1985) y no entra en vigor hasta que el texto se publica íntegramente y pasan quince días hábiles (art. 66.1, Decreto 179/1995). Igualmente, debe publicarse en el boletín informativo local, cuando lo haya, en el tablero de anuncios de la corporación y anunciarse en el Diario Oficial de la Generalitat de Cataluña la referencia del boletín oficial de la provincia en el que se haya publicado íntegramente el texto (art. 66.1, Decreto 179/1995).

\section{Partes habituales de un reglamento}

Ejemplificamos este punto con un articulado de aplicación en una biblioteca pública que trabaje en red. Si se utiliza el siguiente texto para confeccionar el articulado de un centro, hay que tener en cuenta que no se trata de un reglamento real sino de un catálogo de cláusulas, que quiere ser exhaustivo, de puntos a considerar.

4.1. Introducción, preámbulos y carnés

Los reglamentos comienzan por una introducción o presentación general de la biblioteca, su misión, sus servicios y áreas, y del propósi-

\section{Generalidades}

Este reglamento regula la prestación pública de servicios de la biblioteca (...).

La biblioteca (...) es de titularidad municipal de acuerdo con lo que dispone al artículo $26.1 \mathrm{~b}$ de la Ley $7 / 1985$, de 2 de abril, reguladora de las bases de Régimen Local, el artículo 64 de la Ley 8//987, de 15 de abril, Municipal y de Régimen Local de Cataluña, y el artículo 39 de la Ley 4/1993, de 18 de marzo del Sistema Bibliotecario de Cataluña. Por otro lado también respeta la ley Orgánica 15/99 de protección de datos de carácter personal.

La biblioteca (...) tiene como objetivo principal ofrecer a todos los habitantes de (...) instrumentos que ayuden a satisfacer las necesidades de información, formación y cultura, constituyéndose en un centro de acceso a la información y de promoción de la lectura. A pesar de todo, abre también sus puertas solidariamente a vecinos de otros municipios.

Los servicios y prestaciones de la biblioteca (...) son:

- Consulta en sala: acceso a un fondo general al alcance de los usuarios de libros, revistas, vídeos, cd-rom, dvd, entre otros.

- Servicio de información general y local.

-Préstamo de documentos del propio fondo.

-Préstamo interbibliotecario de documentos de colecciones de otros bibliotecas públicas.

-Formación de usuarios en el uso de la biblioteca y de las herramientas de acceso a la información.

- Servicio de reprografía.

-Programación cultural y de fomento de la lectura.

- Servicio público de internet.

-Documentos de libre disposición.

La biblioteca (...) está distribuida en las siguientes áreas:

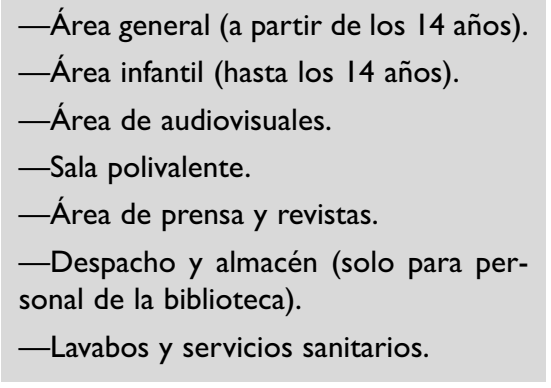

to del reglamento, su alcance, y del marco legal vigente.

Las bibliotecas utilizan ampliamente un tipo de documento de transacción, el carné. Es útil agrupar todos los artículos relacionados con este punto en un apartado. Hay que aclarar:

—En qué situaciones es necesario presentarlo.

—La responsabilidad en su uso.

- La responsabilidad en la corrección de los datos correspondientes a la ficha del usuario.

-Requisitos para obtenerlo. En el caso de los inmigrantes y personas de paso, es el capítulo más variable: algunas bibliotecas acep$\tan$ cualquier tipo de documento, otras piden una prueba de residencia en el municipio. También suelen aparecer añadidos en el caso de los niños o de las instituciones.

—Su validez y alcance.

-Precio del carné o del hecho de ser socio.

\section{Carné de la biblioteca}

I.I. La presentación del carné es indispensable para utilizar los servicios de préstamo, préstamo interbibliotecario, acceso a internet, visionado, audición o cualquiera otro que indique el personal de la biblioteca.

I.2. El carné es personal e intransferible: una persona no puede ceder su carné a otra para acceder al servicio de préstamo o al servicio público de internet. Excepciones son los casos de los familiares de enfermos graves expresamente autorizados o los padres que toman material infantil para sus hijos (no así si el material es para adultos).

I.3. La validez del carné será en principio indefinida. Si un usuario no utiliza el 
carné de préstamo durante 5 años, el sistema informático lo dará de baja automáticamente.

I.4. Para obtener el carné es necesario mostrar el DNI o el carné de conducir. En caso de los menores de 14 años, el padre, la madre, el tutor o la tutora deberá rellenar un impreso de autorización. Las personas de nacionalidad extranjera deberán mostrar el pasaporte o carné de residencia y dejar una dirección de contacto en el municipio, constatable mediante hoja de empadronamiento o factura de luz, gas o teléfono. Los turistas o trabajadores temporales en el municipio podrán obtener un carné provisional de un mes de duración presentando el DNI, pasaporte o carné de conducir y efectuando un depósito, según tarifas vigentes, que se devolverá al dar de baja el carné.

I.5. Se hará siempre el carné en presencia del interesado, excepto en el caso de los niños.

I.6. En caso de que la dirección que conste en el documento de identificación presentado no sea del municipio o del área próxima a la biblioteca, se puede pedir algún documento que justifiqué la vinculación con la localidad (trabajo, estudios, empadronamiento etc.).

1.7. La pérdida o robo del carné debe comunicarse inmediatamente a la biblioteca con el fin de evitar usos indebidos. La expedición de un duplicado del carné o de un nuevo carné se hará según las tarifas vigentes; si se justifica la pérdida del carné con la correspondiente denuncia de robo, la restitución del carné será gratuita.

I.8. En caso de deterioro del carné por causa del uso, la expedición del duplicado será gratuita.

1.9. Hay que comunicar a la biblioteca cualquier cambio de domicilio o de teléfono para posibilitar las reclamaciones de documentos en préstamo, el aviso de documentos reservados o pedidos por préstamo interbibliotecario, la pérdida de carnés, etc. En caso de no hacerlo, el usuario será el único responsable de los perjuicios que puedan derivarse: no poder reclamar los préstamo, no poder avisar las reservas, etc.

I.I0. El carné es válido en toda la red de bibliotecas, igualmente los carnés emitidos por otras bibliotecas de la red pueden utilizarse en la biblioteca (...); en este caso atendiendo a las especificaciones de cada centro.

I.I I. En el caso de las entidades hay que presentar el DNI de la persona respon- sable (presidente, director, gerente, etc.).

I.12. La validez del carné de préstamo es indefinida, y los datos se actualizan cada cinco años.

I.I3. Los datos personales que facilitan los usuarios para obtener el carné serán incluidos en el fichero del sistema integral de gestión bibliotecaria de la red de bibliotecas con la finalidad de gestionar las actividades organizadas por las entidades vinculadas a la Red de bibliotecas.

I.14. Los usuarios podrán ejercer los derechos de acceso, rectificación, oposición y cancelación en los términos establecidos por la legislación vigente, mediante escrito presentado a (...).

4.2. Derechos y deberes de los usuarios

Es el capítulo más delicado: el motivo que normalmente impulsa a los responsables de una biblioteca pública a aprobar un reglamento es marcar el límite a un grupo de usuarios poco cívicos, sobretodo después de experiencias frustrantes. Los derechos van con los deberes, y ambos son parte de una misma cosa.

Los derechos acostumbran a ser más abundantes que los deberes, pero los deberes son más difíciles de concretar; ¿qué quiere decir "mantener el orden en la biblioteca"? Explicarlo puede significar una larga enumeración de conductas no permitidas, pero vale la pena realizar este esfuerzo si después nos allanará el camino en el trato con los usuarios conflictivos.

Al redactar los derechos vale la pena ser exhaustivo, a veces se trata de poner por escrito hechos que damos por supuestos.

En el caso de los deberes es habitual que los reglamentos se pierdan en los detalles y pasen por alto la cuestión de fondo: si decimos "no se puede gritar, ni tener conectados los móviles" en realidad lo que manifestamos es que en la biblioteca hay que respetar un cierto orden; y al redactarlos algunos re- cuerdan unos ejemplos concretos de trasgresión del orden y otros un conjunto de ejemplos diferentes. Si vamos a la cuestión de fondo descubriremos que, en realidad, los deberes de los usuarios corresponden a un grupo pequeño de pautas generales:

—El orden de la biblioteca.

- La seguridad de los usuarios, del equipamiento y del personal que trabaja.

-El respecto al personal de la biblioteca.

La trasgresión de los deberes lleva a restricciones en el uso de la biblioteca, por eso acostumbran a presentarse conjuntamente o a continuación. En general, las restricciones son proporcionales a la gravedad del hecho transgredido:

-Exclusión temporal de los servicios prestados, normalmente de un día.

-Multas.

—Reposición de los bienes siniestrados.

-Expulsión definitiva de los servicios de la biblioteca.

También es habitual considerar la severidad de la restricción ante la repetición de la misma falta.

Continúa en la p. 151

\section{Derechos y deberes de los usuarios de la biblioteca}

2.I. Los derechos de los usuarios de la biblioteca son:

2.I.I. Disfrutar de los espacios de la biblioteca dedicados a consulta sin más limitación que las previstas en el presente Reglamento.

2.1.2. Recibir los servicios de manera libre y gratuita. Son gratuitos la consulta en sala, el préstamo de todo tipo de fondo de la propia biblioteca, la consulta de Internet. Algunos de los servicios, como el préstamo interbibliotecario, el servicio de reprografía, las grabaciones e impresiones de Internet son susceptibles de ser cobrados de acuerdo con las ordenanzas de precios públicos de las instituciones que gestionan la biblioteca.

2.1.3. Consultar en libre acceso el fondo 
de la biblioteca, que está constituido por libros, periódicos, revistas, vídeos, $C D$ musicales, CD-ROM, casetes, disquetes $y$ otros documentos en diferentes formatos.

2.1.4. Ser informado de los diferentes servicios y prestaciones que se ofrecen en la biblioteca, así como de sus normas de uso, de manera personalizada.

2.1.5. No ser discriminado por causa de sexo, edad, condición económica, país de procedencia o religión.

2.1.6. Recibir asistencia y formación sobre como utilizar de manera óptima el fondo y los servicios de la biblioteca.

2.I.7. Consultar los catálogos informatizados para conocer el fondo de la biblioteca.

2.1.8. Consultar los catálogos informatizados para conocer el fondo de las bibliotecas de la Red.

2.1.9. Recibir en préstamo documentos de la biblioteca o de otros centros bibliotecarios.

2.I.10. Participar en las actividades culturales programadas.

2.I.I I. Presentar las sugerencias y reclamaciones sobre el funcionamiento de la biblioteca que consideren convenientes en el buzón previsto a este efecto.

2.1.12. Sugerir fondo para que la biblioteca lo adquiera.

2.I.13. Ser tratados con el máximo respeto y consideración por todo el personal de la biblioteca.

2.I.14. Disponer, dentro de la biblioteca, de materiales e información representativos de todos los puntos de vista sobre cuestiones actuales.

2.I.I5. Recibir discreción y confidencialidad respecto de sus datos personales, sus peticiones y sus lecturas, excepto en el caso de requerimiento judicial.

2.1.16. Acceder a su ficha personal a través del OPAC de la biblioteca.

2.I.17. Recibir por parte del personal de la biblioteca las respuestas calificadas $y$ correctas a las cuestiones demandadas.

2.I.18. Ser avisados de algún posible error cometido por el personal de la biblioteca y a su enmienda, facilitando la información pertinente.

2.I.19. Y aquellos otros especificados en el resto de artículos del presente Reglamento.

2.2. Los deberes de los usuarios de la biblioteca son:

2.2.I. Mantener el orden en la biblioteca.

2.2.I.I. Lo cual se puntualiza de la siguiente manera: dentro de las instalacio- nes de la biblioteca no se permite fumar o encender fuego, comer, beber (se permite llevar botellas de agua pero no dejarlas sobre las mesas), dormir; utilizar teléfonos móviles o alarmas de relojes; poner en marcha equipos de reproducción de sonido propios de manera audible para el resto de usuarios; ensuciar; hacer jaleo, luchar, lanzarse objetos o empujarse, jugar a juegos no autorizados - hacer rodar pelotas; cantar o silbar; molestar a propósito o amenazar a otros; emplear un lenguaje grosero o racista; invadir la intimidad de otros usuarios; reservar mesas o lugares de estudio para otras personas; estar bajo los efectos del alcohol o de drogas; poner los pies sobre las mesas o las sillas; malograr o destruir bienes de la biblioteca; abrir las puertas de emergencia, excepto en caso de alarma justificada; pedir dinero, vender loterías, apostar, vender ambulantemente cualquiera tipo de mercancía, dejar propaganda sin pedir permiso, pedir un voto determinado en campañas electorales; utilizar los lavabos de la biblioteca para bañarse, afeitarse, cambiarse de ropa (sí está permitido a las madres amamantar a sus hijos o cambiarles los pañales en los lavabos, pero no en la sala infantil); entrar en la biblioteca con animales de compañía (sí están permitidos los perros lazarillo), vehículos recreativos (como bicicletas, monopatines, patinetes...); enchufar aparatos propios en la instalación eléctrica de la biblioteca, excepto en los lugares señalizados para ordenadores portátiles; desplazar el mobiliario de la biblioteca de su lugar inicial; abandonar en la biblioteca a personas que requieren atención especial (niños de menos de 7 años, enfermos mentales, ancianos en silla de ruedas...); entrar en zonas de almacén u oficina cerradas al público general; abalanzarse sobre los mostradores de trabajo y tomar los objetos; estar en la biblioteca sin utilizar ningún servicio.

2.2.1.2.En la sala infantil y en la sala de revistas se permite un tono de conversación moderado. En la sala de adultos se ruega mantener silencio total; los adolescentes, que a pesar de haber cumplido 14 años, no puedan cumplir esta pauta serán invitados a desplazarse a la sala infantil o a abandonar la biblioteca.

2.2.1.3. Los cochecitos de niño se dejarán en la zona de la sala infantil especialmente habilitada para este efecto.

2.2.2. Contribuir a la seguridad del Centro.

2.2.2. I. El personal de la biblioteca se reserva el derecho a inspeccionar cualquier bolsa o mochila bajo la firme sospecha de hurto. Los usuarios tienen a su disposición las taquillas de la planta baja para depositar las bolsas de mano.

2.2.2.2. La biblioteca, por cuestiones de seguridad, vacía cada noche la consigna de la planta baja. Los objetos encontrados se conservan durante dos días en el mostrador de información de la segunda planta, transcurrido este tiempo se destruyen.

2.2.2.3. Los usuarios deben vigilar sus pertenencias. La biblioteca no se responsabiliza de pérdidas o robos. A pesar de ello, todos los objetos encontrados podrán ser recuperados por sus propietarios en el mostrador de información de la segunda planta de la biblioteca, en el plazo de dos días, pasados los cuales los objetos serán destruidos.

2.2.2.4. Los usuarios deben alertar al personal de la biblioteca de cualquier accidente $o$ incidente que ponga en riesgo la seguridad de las personas y de los bienes.

2.2.2.5. Los usuarios deben identificarse con el carné de la biblioteca o los documentos válidos para hacerse el carné a requerimiento del personal de la biblioteca.

2.2.3. Respetar al personal de la biblioteca. El personal bibliotecario se obliga a tratar a los usuarios con cortesía y eficiencia profesional, y de ellos reclama respeto. En cualquier caso, el personal bibliotecario no tolerará insultos personales, comentarios peyorativos o denigrantes sobre su persona o la dignidad de las instituciones para las que trabaja.

2.2.4. Actuar con responsabilidad respecto a los niños.

2.2.4.I. Los niños menores de 7 años irán acompañados de un adulto o niño mayor de 14 años en las salas, y si necesitan ayuda en el lavabo deberán pedirla a sus acompañantes o cuidadores.

2.2.4.2. Los usuarios menores de edad, vayan o no acompañados, no serán responsabilidad del personal de la biblioteca. En el caso de quedar solos momentaneamente, el personal bibliotecario no se responsabiliza de las entradas o salidas del menor.

2.2.4.3. En cualquiera caso, queda del todo prohibido dejar solos a los menores de 7 años; en caso de reincidencia del abandono, la situación será puesta en conocimiento de los asistentes sociales del Ayuntamiento.

2.2.4.4. Los padres o los adultos que acompañan a los niños a la biblioteca deben intentar que el niño no corra descontrolado, grite, llore desconsoladamente o vacíe las estanterías a modo de juego. Si los padres o adultos acompañantes no pueden controlar al niño, se 
les pedirá a ambos que abandonen la biblioteca.

2.3. Medidas sancionadoras.

2.3. I. La infracción de estas pautas (2.2.I a 2.2.4 y sus apartados) llevará primero a una advertencia verbal, después a la exclusión de la biblioteca durante un día y la repetición de la infracción llevará a excluir el usuario durante una semana; en casos muy graves se hará efectiva la expulsión definitiva.

2.3.2. La persona que esté en desacuerdo puede dirigir una queja formal por escrito al director de la biblioteca, que la estudiará y contestará en el plazo máximo de una semana.

2.3.3. En caso de menores de edad, la expulsión será notificada a los padres o tutores legales mediante una carta, donde constará el período de expulsión y la causa que ha motivado los hechos.

2.3.4. La expulsión definitiva de la biblioteca será posterior a un informe a la Regidoría de Cultura, que se elevará a la Alcaldía-Presidencia para que dicte resolución.

2.3.5. Las medidas que se prevén en este apartado se aplicarán sin perjuicio de las acciones, civiles o penales que correspondan según la legislación vigente.

2.3.6. En los casos no previstos por esta normativa, el director de la biblioteca, con la autoridad delegada de las instituciones que la crearon y la gestionan, establecerá las pautas pertinentes teniendo en cuenta la integridad de las instalaciones, la seguridad y el bienestar del conjunto de usuarios y del personal de la biblioteca

Viene de la p. 149

Ya hemos dicho que definir qué es el orden en la biblioteca resulta harto complicado, incluso algunas pautas en este sentido pueden resultar chocantes. En las bibliotecas públicas de EUA hemos encontrado estos casos tan curiosos:

-Está prohibido ir con la cara tapada, excepto por motivos médi$\cos$ o religiosos ${ }^{27}$.

-No se permite mover muebles de manera que se bloqueen los pasillos, utilizando mesas, sillas o estufas $^{28}$.

—No está permitido comer o estar en posesión de paquetes y contenedores de comida abiertos ${ }^{28}$.
- Los usuarios deben ir vestidos adecuadamente; zapatos y camisetas son obligatorias $29,31,35,38$.

-No está permitido molestar a otros discutiendo, haciendo propaganda, distribuyendo literatura o predicando ${ }^{29}$.

—No se permite el lenguaje o los gestos obscenos ${ }^{30}$.

- Cuando los grupos de usuarios que se sientan juntos son una fuente de ruido inaceptable, se les podrá pedir que cambien de lugar ${ }^{30}$.

-No se permite interferir el paso libre de los demás ${ }^{34}$.

-No está permitida la actividad sexual ${ }^{35}$.

-Está prohibido estar en posesión de armas o de objetos que podrían utilizarse como armas (p. ej. objetos filosos, colgadores de la ropa, archivadores metálicos o pins) ${ }^{35}$.

-No están permitidas siestas prolongadas (que excedan de 30 minutos) o roncar ruidosamente ${ }^{35}$.

-No está permitido el olor corporal causado por exceso de perfume o de colonia, de tal manera que provoque quejas generales o incomodidad a otros usuarios de la biblioteca $^{36}$.

-No están permitidas las demostraciones excesivas de afecto ${ }^{36}$.

-No se pueden llevar a la biblioteca sacos de dormir y mantas ${ }^{36}$.

- No se puede ocupar más de un asiento o espacio de estudio por persona $^{36}$.

—Está prohibido tener equipaje o bolsas grandes en la biblioteca ${ }^{37}$.

-Está prohibido escupir a cualquier persona, a los muebles o al suelo ${ }^{37}$. La misma biblioteca también prohíbe masticar tabaco.

-Está prohibido permanecer en la biblioteca después de la hora de cierre ${ }^{37}$.
—Está prohibido utilizar la biblioteca para dormir, bañarse o enjuagar o secar objetos personales ${ }^{37}$.

-Está prohibido que falta de higiene corporal ofenda de tal manera que sea una molestia para otras personas $^{37}$.

-Está prohibido dedicarse a cualquiera forma de desviación sexual, incluida la exposición, los tocamientos ofensivos y el acoso sexual a otros usuarios o al personal de la biblioteca ${ }^{37}$.

-Es ilegal llevar armas de cualquiera tipo, escondidas o a la vista, excepto para los agentes de la $1 e y^{38}$.

- Los usuarios no asediarán a otros usuarios mirándolos fijamente con la intención de molestarlos, tampoco los seguirán por el edificio $^{39}$.

Quizá, algunas de las restricciones aquí expuestas nos hagan sonreír, pero detrás hay tragedias personales y bibliotecarios muy frustrados, incluso impotentes, que se amparan de un reglamento.

Hasta aquí se han tratado de condiciones generales de acceso.

A continuación, una buena manera de ordenar la información y de no olvidar ningún apartado es pasar por todos los servicios de la biblioteca.

Continúa en la p. 156

\section{Consulta en las salas}

La biblioteca dispone de tres salas: la sala infantil para menores de 14 años, la sala de adultos para los mayores de 14 años y la sala de revistas, sin limitación de edad.

\section{I. En general:}

3.I.I. La biblioteca abrirá al público los días y las horas que se indiquen públicamente y que podrán ser modificados a criterio del Ayuntamiento.

3.I.2. El fondo está ordenado según la Clasificación Decimal Universal y la Clasificación de Grabaciones Sonoras.

3.I.3. El cierre de la biblioteca a causa de festivos y días de descanso del personal se anunciará como mínimo una semana antes mediante carteles fijados en el 


\section{portal de acceso a la biblioteca.}

3.1.4. La biblioteca podrá cerrar sus instalaciones parcial o totalmente, por causa de bajas por enfermedad de más del $50 \%$ de su personal, o en casos de fuerza mayor.

3.I.5. El acceso a los documentos es de libre acceso a casi todas las salas. Para acceder a la colección local hay que dejar el carné en el mostrador de información y acceder a las vitrinas.

3.I.6. En una silla sólo puede sentarse una persona. No pueden desplazarse las sillas de su lugar asignado.

3.I.7. Una vez consultados, los documentos se dejarán en los carros y lugares señalizados para que el personal pueda ordenarlos correctamente. Los diccionarios y enciclopedias, deben dejarse directamente en su estante.

3.I.8. Ante la gran demanda de lugares de estudio en época de exámenes, la biblioteca reserva determinadas mesas para usos concretos: las mesas de la sala de revistas están reservadas a los usuarios que quieran consultar revistas o periódicos, y las butacas de la sala de audios para audiciones; en la sala de adultos, también hay mesas señalizadas para la consulta exclusiva de documentos de la biblioteca.

3.1.9. Los usuarios deben cuidar de los documentos (libros, periódicos, revistas, vídeos, etc.) que consulten y del mobiliario, en el caso de daños (manchas, pliegues, rallas, sustancias pegajosas, recortes, etc.) se exigirá la reposición del bien siniestrado.

3.I.10. Los usuarios atrapados hurtando documentos u otros bienes de la biblioteca serán expulsados definitivamente de todos los servicios de la biblioteca. Esta medida es independiente de las acciones civiles o penales que puedan emprenderse según la gravedad del caso.

3.I.I I. Se podrá acceder a las salas hasta diez minutos antes del horario de cierre de la biblioteca.

\subsection{Sala de adultos.}

3.2.I. No se permite dejar ningún libro, carpeta $u$ objeto personal en las mesas de la sala de adultos para guardar lugar a otras personas. Una vez transcurridos 10 minutos del abandono de objetos, se retirarán de las mesas; su propietario podrá reclamarlos en el plazo de dos días en el mostrador de información de la segunda planta, pasados estos dos días los objetos abandonados se destruirán.

3.2.2. En la sala de adultos no está permitido hacer trabajos en grupo o de tipo manual (con cartulina, pegamento, ti- jeras, etc.).

3.2.3. Las salas de estudio pueden utilizarse para hacer trabajos en grupo, dentro del orden y pautas generales de convivencia de la biblioteca. En caso de conflicto, los usuarios de las salas de estudio serán desalojados. El aforo máximo de las salas de estudio queda a criterio del personal de la biblioteca.

\subsection{Sala de audios.}

3.3.l. Para visionar vídeos o escuchar documentos en formato audio en la sección de audiovisuales, hay que tener el carné de préstamo. El usuario deja el carné en el mostrador y recibe a cambio unos auriculares para escuchar la grabación. Queda prohibido consultar cualquier cd, vídeo o dvd que no sea del fondo de la biblioteca en los aparatos reproductores habilitados en las salas. En la sala de audios, la audición de cd o el visionado de vídeos es individual; en la sala infantil, para el visionado de vídeos se permite un máximo de dos personas.

3.3.2. La consulta de vídeos y canales vía satélite se limita a un máximo de una hora por persona y día (tanto en el caso de niños como de adultos). Los niños que visionen vídeos deben acabar del todo una cinta antes pedir otra. La consulta de cd tiene un tiempo máximo de 15 minutos.

3.3.3. El servicio de audición de música y visionado de películas finalizan 30 minutos antes de cerrar la biblioteca.

\subsection{Sala de revistas.}

3.4. I. Las revistas y periódicos sólo pueden leerse dentro la hemeroteca.

\subsection{Sala infantil.}

3.5.I. En la sala infantil hay que pedir número para sentarse a una mesa, que deberá conservarse hasta salir. En la mesa sólo puede haber cuatro personas. El personal de la biblioteca puede cambiar a los usuarios infantiles de lugar para mantener el orden y evitar alborotos.

3.5.2. En la sala infantil hay unas mesas reservadas para adultos y que no pueden ser ocupadas por niños que hacen trabajos.

3.5.3. En la sala infantil, en días con una gran afluencia de público, será prioritaria la estancia de los usuarios que utilicen los materiales y servicios de la biblioteca. Si el personal de la biblioteca observa la falta de lugares para la consulta, podrá pedir a los usuarios que sólo consultan sus apuntes o libros personales que cedan sus lugares.

3.5.4. Los usuarios menores de 14 años no pueden acceder a las zonas reservadas a los adultos, excepto en los casos permitidos por los responsables de la biblioteca.

\section{Servicio de información}

4.I. Las consultas dirigidas al servicio de información son confidenciales $y$ en principio anónimas.

4.2. El servicio de información y consulta por teléfono sólo se ofrecerá durante el horario de apertura de la biblioteca.

4.3. Las consultas que, por su complejidad, no puedan resolverse inmediatamente, serán atendidas en el plazo máximo de dos días.

\section{Servicio de préstamo}

El servicio de préstamo tiene como finalidad permitir la cesión gratuita y temporal de documentos (libros, vídeos, $\mathrm{dvd}, \mathrm{cd}, \mathrm{cd}$-rom, etc.) de la biblioteca a un usuario.

5.I. Generalidades, documentos excluidos, plazos y número de documentos.

5.I.I. Cualquier persona que quiera llevarse documentos debe pasar por el servicio de préstamo; en caso de no hacerlo, le pueden ser aplicadas las sanciones establecidas.

5.I.2. Se establece un período general de 21 días naturales para un libro y 7 días naturales para documentos no libro. En períodos de vacaciones pueden pedirse plazos más largos. Algunos documentos de gran demanda (manuales para preparar oposiciones, guías de viaje recientes, material para realizar trabajos escolares, etc.) podrán salir en préstamo especial o restringido de una semana.

5.I.3. Excepciones de préstamo. Pueden ser objeto de préstamo todos los materiales que integran el fondo de la biblioteca a excepción de: las obras de referencia (enciclopedias, diccionarios, atlas, etc.), últimas ediciones de recopilaciones de leyes, los ejemplares únicos de colección local, el último número de las revistas, los periódicos, los dossiers de prensa y otros documentos similares que, a criterio del director de la biblioteca, deban ser excluidos del servicio de préstamo. Estos documentos pueden ser fotocopiados en el servicio de reprografía.

5. I.4. El carné de lector autoriza a tener en préstamo simultáneamente un total de 13 documentos en toda la red de bibliotecas, de los que un máximo de 6 serán libros ( 3 del mismo tema, 2 de colección local), 3 vídeos o dvd, $3 \mathrm{~cd}$ musicales, 3 revistas. Las entidades pueden superar esta cantidad de documentos en préstamo.

5.I.5. Es imprescindible presentar el carné de la biblioteca para realizar el prés- 
tamo, o en su defecto el DNI, carné de conducir, pasaporte o carné de residencia.

5.I.6. Los documentos deben entregarse al personal de los mostradores de préstamo señalizados y esperar a que el personal de la biblioteca haya completado todas las comprobaciones pertinentes (que los vídeos o dvd corresponden a las cajas, etc.). Si no es así pueden producirse malentendidos y el usuario puede afrontar reclamaciones de documentos perdidos o no retornados. También pueden devolverse en los buzones de retornos.

5.I.7. Los documentos siempre deben retornarse en la biblioteca donde se han tomado en préstamo. Si se quiere efectuar la devolución en otro centro bibliotecario hay que consultarles directamente en qué condiciones se realiza este servicio. Por su parte, la biblioteca acepta el retorno de documentos prestados por otros centros y se compromete a hacerlos llegar, siempre que se abone la tarifa de transporte establecida.

5.I.8. El horario del servicio de préstamo finalizará 10 minutos antes del horario de cierre del conjunto de la biblioteca.

5.1.9. Las cintas de vídeo deben retornarse rebobinadas. Hay que coger los discos compactos y los dvd con cuidado y evitarles ralladuras.

\subsection{Renovaciones.}

5.2.I. Pueden solicitarse renovaciones de estos períodos siempre que los documentos no estén reservados por otro usuario y que la solicitud de renovación se haga antes de que venza la fecha de retorno. Se podrán hacer dos renovaciones por teléfono, si se quiere renovar un documento más veces hay que hacerlo presencialmente en la biblioteca llevando el documento en cuestión.

5.2.2. Se podrán realizar renovaciones por teléfono dentro del horario de apertura de la biblioteca.

\subsection{Reservas.}

5.3.I. Si el documento que se quiere solicitar está en préstamo, puede reservarse personalmente en la biblioteca $\circ$ a través del web de la biblioteca.

5.3.2. Cualquier usuario puede reservar un máximo de dos documentos que estén en préstamo, exceptuando los que están excluidos; todos los períodos de préstamo pueden ser renovados hasta dos veces, siempre que no exista una reserva previa de otro usuario sobre el documento.

5.3.3. Cuando el documento sea devuel- to, la biblioteca lo comunicará al usuario que haya reservado, mediante una llamada telefónica. Si después de llamar al usuario cinco veces en cinco días sucesivos no se le puede localizar, el documento perderá la reserva. Por otro lado, superado un período de 7 días hábiles desde el aviso, si el documento no ha sido retirado por el usuario, será puesto a disposición del público en general. En el caso de documentos con múltiples reservas, el período de espera es de 3 días hábiles.

5.3.4. No se realizarán reservas o renovaciones a los usuarios con documentos prestados fuera de plazo.

5.3.5. En caso de que se reserve un documento de otra biblioteca, el usuario deberá ir a recogerlo a la biblioteca en cuestión.

5.3.6. En caso de que un usuario no pase a recoger los documentos que tiene reservados será sancionado con la restricción del servicio de reservas durante tres meses. Si este comportamiento se repite, la segunda vez la restricción será por un año.

\subsection{Retornos con retraso.}

5.4.I. El prestatario que no cumpla los plazos de préstamo será sancionado con un día de suspensión del servicio de préstamo, préstamo interbibliotecario y de internet por cada día de retraso. La suspensión será efectiva en toda la red de bibliotecas y comenzará a contar a partir del día en que se hayan retornado todos los documentos; así retornar una parte de los documentos en préstamo no es excusa por continuar atrasándose.

5.4.2. Para los usuarios que han sido objeto de reclamación más de tres veces, las sanciones aumentarán progresivamente. A la cuarta reclamación se penalizará con 2 días por cada día de retraso, a la quinta reclamación 3 días por cada día de retraso, a la sexta reclamación 5 días por cada día de retraso, a la séptima reclamación 7 días por cada día de retraso, y en la octava reclamación exclusión de un año.

5.4.3. Los procedimientos para reclamar los documentos no retornados serán: llamadas telefónicas preferentemente o en su defecto cartas. Tanto números de teléfono como direcciones postales deben ser provistas y actualizadas por los usuarios en caso de cambios, si eso no es así el usuario puede afrontar situaciones incómodas.

5.4.4. Si los datos personales facilitados por el usuario son incorrectos, el teléfono se encuentra desconectado, no tiene contestador, o bien no tiene constancia de nuestra reclamación, la sanción será igualmente aplicable.

5.4.5. En casos muy graves de usuarios que desatienden las llamadas telefónicas y también dos reclamaciones por carta se les excluirá de todos los servicios de la biblioteca.

5.5. Pérdidas y documentos malogrados.

5.5.I. La biblioteca puede no aceptar la devolución de un material deteriorado, o bien un disco rayado, o con la caja rota.

5.5.2. Los usuarios deben tener cuidado de los documentos que piden en préstamo y advertir al personal de la biblioteca de cualquier desperfecto que hayan observado.

5.5.3. El prestatario está obligado a reponer la obra perdida o deteriorada, sea antigua o nueva. En caso de no cumplir esta norma, se suspenderá la efectividad del carné de préstamo en toda la red. Es necesario que el usuario se responsabilice de reponer un ejemplar igual al documento prestado. En caso de que eso no sea posible (documentos agotados, descatalogados, etc.) el usuario abonará su importe (de acuerdo con el precio que consta en el catálogo de la biblioteca o en el ISBN). En caso de que sea imposible fijar el precio de la obra no retornada se aplicará una tarifa fija, aprobada por el pleno municipal. Este dinero se destinará a la compra de documentos similares o que actualicen los perdidos.

5.5.4. Igualmente, el usuario deberá afrontar los gastos de preparación del documento (forros, dispositivos antihurto, etiquetas, etc.) según las tarifas vigentes.

5.5.5. Cuando el deterioro sufrido por el documento se limita al forro o a las cajas contenedoras se hará abonar al usuario una cantidad según las tarifas vigentes.

5.5.6. Un usuario que haya perdido o que devuelva un documento deteriorado, quedará excluido del servicio de préstamo hasta que haya adquirido el mismo documento y lo restituya a la biblioteca.

5.5.7. Cuando el material se ha repuesto, el usuario puede utilizar los servicios de la biblioteca con normalidad, siempre y cuando el plazo de reposición no haya sido superior a tres meses. En caso de que el usuario haya tardado más de tres meses en reponer el material, la exclusión del servicio de préstamo y de internet será de 6 meses por cada 3 meses de retraso en la reposición.

5.5.8. En caso de que un usuario preste 
los documentos pedidos en préstamo a otra persona o entidad, y este segundo los pierda o deteriore, el único responsable de los documentos será el usuario que los retiró en préstamo de la biblioteca.

\section{Servicio de préstamo interbi- bliotecario}

La biblioteca actúa como: I) intermediaria, al pedir documentos para sus usuarios. Este servicio permite ampliar los recursos bibliográficos de la biblioteca, facilitando el acceso a publicaciones existentes en otros centros; 2 ) suministradora, cuando recibe peticiones de documentos de otras bibliotecas.

6.I. En caso de actuar como intermediaria:

6.I.I. Este servicio se realizará después del pago previo del gasto originado en concepto de transporte, fijado según tarifas aprobadas. También deberá afrontarse el gasto en el caso de reservas hechas por internet que generan desplazamiento de documentos entre bibliotecas.

6.1.2. Este servicio se rige por las normativas de préstamo del centro propietario del documento.

6.1.3. Para pedir documentos mediante el servicio de préstamo interbibliotecario, el usuario deberá tener dado de alta el carné de la biblioteca.

6.I.4. Los documentos pedidos a la red de bibliotecas se recibirán en la bibliote$\mathrm{ca}$, en un plazo que puede variar, normalmente de 7 a 15 días hábiles. El retorno de los documentos se efectuará, dentro del período normal de préstamo, en la propia biblioteca.

6.I.5. Dentro de la red de bibliotecas quedan excluidos de este servicio los documentos audiovisuales, así como cualquier otro material que pueda ser considerado como excluido por parte de la biblioteca de origen.

6.I.6. En caso de malograr el documentos pedido fuera, el usuario deberá hacerse cargo de la reposición o compensación.

6.I.7. En cuanto a los préstamos interbibliotecarios avisados que nadie viene a retirar pasados 7 días hábiles del aviso, 0 tras llamar repetidamente durante 5 días hábiles, se retornarán a la biblioteca de origen. Si el usuario quiere volver a pedir el documento deberá abonar otra vez los gastos de transporte.

6.1.8. Quedan excluidos de este servicio las personas con documentos pendientes de devolución.

6.2. En caso de actuar como suministra- dora:

6.2.I. Los documentos que pueden dejarse en préstamo interbibliotecario son los mismos que pueden salir en el servicio de préstamo ordinario. Consúltese la sección de préstamo.

6.2.2. Adicionalmente, también se excluirán de préstamo interbibliotecario las novedades editoriales y los documentos que puedan obtenerse fácilmente por otros medios, así como la colección local. En el catálogo constarán como "excluidos de PI".

6.2.3. La biblioteca, en última instancia, se reserva el derecho de denegar un préstamo interbibliotecario por motivos técnicos o de oportunidad.

6.2.4. Los documentos cedidos en préstamo interbibliotecario pueden ser reclamados en cualquier momento con motivo de necesidades propias.

6.2.5. Las condiciones de renovación del préstamo interbibliotecario serán las mismas que las de préstamo ordinario.

6.2.6. La seguridad del material es responsabilidad de la biblioteca peticionaria, la cual asumirá los costes de reposición en caso de pérdida o daño.

6.2.7. El envío y el retorno se hará con el documento correctamente empaquetado y protegido.

\section{Servicio de formación de usuarios}

7.I. Hay que acordar cita previamente en el caso de formación para grupos.

7.2. Los grupos escolares deberán presentarse acompañados de adultos en proporción de un adulto acompañante por cada 20 niños. Su función será guiarles hasta la biblioteca y mantenerlos en orden en la parte de la visita dedicada a uso libre de la biblioteca.

7.3. Los grupos deberán presentarse a la hora acordada.

\section{Servicio de reprografía}

8.I. En principio, pueden fotocopiarse todos los documentos de la biblioteca.

8.2. Las fotocopiadoras de la biblioteca funcionan en régimen de autoservicio.

8.3. La biblioteca no se compromete a disponer siempre de cambio para hacer fotocopias.

8.4. El material de la biblioteca hay que tratarlo con cuidado y no malograrlo.

8.5. En las fotocopiadoras de la biblioteca sólo se puede reproducir el fondo bibliográfico del Centro.

8.6. Se podrán poner restricciones en algunos casos de solicitudes de reproduc- ción de documentos de fondo específico sobre un soporte determinado, teniendo en cuenta criterios como, por ejemplo, la antigüedad, la calidad y el estado del soporte original, formato o manipulación difícil.

8.7. En caso de que se requiera hacer una fotocopia en el exterior habrá que dejar algún documento identificativo al personal de la biblioteca.

8.8. Hay que respetar la Ley de propiedad intelectual a la hora de realizar reproducciones de documentos: la copia privada con finalidad de estudio o investigación, sin hacer uso colectivo ni con finalidades lucrativas. En caso de reproducir fragmentos de una obra determinada, hay que citar la obra de procedencia.

8.9. El servicio de fotocopias acaba un cuarto de hora antes del cierre de la biblioteca.

\section{Programación cultural}

9.I. Las actividades que organiza la biblioteca son gratuitas para el usuario, en caso contrario así se anunciará en carteles y folletos promocionales de la actividad en cuestión. Se fijarán precios públicos para actividades por su carácter especial, interés restringido o por necesidad de autofinanciación.

9.2. Las actividades que organiza la biblioteca serán de libre acceso para todos los ciudadanos. Por motivos de capacidad o en caso de estar dirigidas a un sector de público determinado se priorizará y limitará el acceso a las actividades.

9.3. Hora del cuento: los niños asistentes a la hora del cuento deberán ir acompañados de un adulto o niño mayor de 14 años que se haga responsable. Los acompañantes deben guardar silencio $y$ respetar el trabajo del cuentista; las personas que interfieran la actividad deberán abandonar la sala con los niños a quienes acompañan.

9.4. La biblioteca tiene un servicio de envío por correo de información sobre la biblioteca y sus actividades: los usuarios inscritos pueden cancelar sus datos personales en el momento en que lo deseen, previa petición personalmente o por escrito.

9.5. En caso de que se prevea que el desarrollo de las actividades afectará a otros servicios, deberá comunicarse con la antelación de 7 días hábiles a los usuarios, con indicación expresa de la causa, los días y las horas en que se producirá y la limitación o suspensión temporal del servicio afectado. 


\section{Servicio público de internet}

La biblioteca dispone de terminales de internet tanto en la sala de adultos como en la infantil.

10.I. Hay que tener y presentar el carné de préstamo de la biblioteca para acceder al servició de internet público. El carné quedará depositado durante la consulta en el mostrador de información.

10.2. Antes de consultar debe pedirse turno en el mostrador de información.

10.3. No pueden utilizar este servicio las personas que tienen documentos en préstamo fuera de plazo o que han estado excluidos de los servicios de la biblioteca.

10.4. La consulta de internet es gratuita.

10.5. El tiempo máximo de consulta es de 30 minutos diarios, y de 4 sesiones a la semana (es decir de 2 horas semanales). Justificadamente también puede pedirse un turno de una hora, igualmente el máximo semanal es de 2 horas.

10.6. También hay a disposición del público un terminal dedicado exclusivamente a consultas rápidas (máximo de 15 minutos), para resolver consultas muy específicas, para el que también hay que pedir turno.

10.7. Los turnos de internet comienzan a las horas en punto y a la media; la persona que pide turno hasta 10 minutos después de que haya comenzado el turno se asigna a este turno; si pasan II minutos se asigna al turno siguiente.

10.8. Si no hay usuarios esperando para consultar, este tiempo puede ampliarse siempre según el criterio del personal de la biblioteca.

10.9. Los usuarios deben facilitar la rotación de los ordenadores por respeto a los usuarios que esperan.

10.10. Pueden reservarse telefónicamente turnos de internet, siempre dentro del mismo día y para una sola sesión.

10.I I. En las reservas de internet, la persona interesada debe estar en la sala correspondiente cinco minutos antes del turno pedido, si no es así el turno podrá cederse a otro usuario.

10.12. Las consultas a internet deben ir dirigidas a la búsqueda de información, la investigación, el aprendizaje o al uso de correos personales. No se permite acceder a chats, juegos, pornografía, erotismo, páginas de contacto o enviar mensajes a móviles. Como primer aviso se excluirá el infractor durante un día, la segunda y sucesivas infracciones llevarán a la exclusión de un mes.
10.13. La excesiva demanda del servicio provocará que se priorice el uso para consulta bibliográfica y el uso cultural o de interés pedagógico, sobre el estrictamente lúdico. También se priorizará a los usuarios nuevos sobre los habituales del servicio de internet.

10.14. La información que se encuentra en internet es provista por millones de personas y organizaciones del mundo entero. No toda la información de internet es correcta, actual, legal o aceptable para todos los individuos. La biblioteca no controla la información que se encuentra en internet $y$, por lo tanto, no puede ser responsable de su contenido. Los usuarios de internet son responsables de evaluar la validez y aquello que es apropiado.

10.15. La biblioteca no ofrece acceso a programas de ofimática, por ejemplo, para redactar trabajos de clase, currículos, etc.

10.16. Servicios de pago: las impresiones y los disquetes para grabaciones son de pago según las tarifas vigentes. El disquete se puede reutilizar tantas veces como se quiera, pero por motivos de seguridad se formatea cada vez.

10.17. Los usuarios pueden pedir la compresión de los ficheros que hayan bajado de internet.

10.18. En cada Pc de trabajo sólo puede haber una persona, el titular del carné que se ha dejado en el mostrador.

10.19. Debe respetarse la privacidad de las consultas de los demás usuarios.

10.20. El personal de la biblioteca se reserva el derecho de finalizar las sesiones en un momento dado por: uso inadecuado de los aparatos, incumplimiento de las normas de la biblioteca y falta de respeto a otros usuarios.

10.21. Internet para los niños. La biblioteca dispone de un Pc conectado a internet en la sala infantil, reservado para niños menores de 14 años. Por las características de internet $y$ de la variedad de contenidos a los cuales se pueden acceder, es obligatorio que los padres autoricen a sus hijos a efectuar este tipo de consultas, rellenando un formulario específico y presentándolo en la sala infantil. La biblioteca invita al adulto responsable del menor a realizar la consulta juntamente con el niño o la niña.

10.22. El servicio público de internet cierra media hora antes que la biblioteca.

10.23. No se puede adeudar dinero por las impresiones de internet o la adquisición de disquetes.
10.24. La biblioteca no conserva información sobre páginas consultadas, pero sí lleva un control sobre turnos diarios dados; esta información puede ser requerida judicialmente.

10.25. No se deben apagar los Pc de internet público.

10.26. No se permite cambiar la configuración de los Pc de la biblioteca. Las personas que lo hagan serán expulsadas del servicio público de internet.

10.27. Los usuarios tienen la obligación de leer cualquier noticia relacionada con temas de copyright que aparezcan en la información consultada y respetarla.

10.28. Ante problemas, los usuarios no intentarán reiniciar los equipos. En este caso deben avisar al personal de la biblioteca.

\section{I. Servicio de documentos de libre disposición}

II.I. El servicio de documentos de libre disposición se nutre de fondo donado a la biblioteca y de fondo propio dado de baja. En este sentido hay que aclarar que La biblioteca acepta la donación de documentos, con la condición de que el destino que se dé puede ser muy diverso, siempre ajustándose a los criterios técnicos de los bibliotecarios, que exponemos brevemente a continuación:

II.I.I. En general, se incorporan al fondo de la biblioteca obras donadas por usuarios que reúnen estas características: perfecto estado de conservación, con contenidos actuales (publicado hace menos de cinco años) e interesantes, títulos nuevos para el fondo de la biblioteca, fondo patrimonial y de la colección local. Se incorporan duplicados en el caso de obras de gran demanda: novelas de tipo best seller recientes y lecturas obligatorias para escolares.

II.I.2. Básicamente, los ejemplares duplicados o que aún pueden tener algún interés se regalan a otras bibliotecas, instituciones sociales (centros de barrio, tiendas solidarias, etc.) o educativas y a los usuarios de la biblioteca mediante el servicio de documentos de libre disposición.

II.I.3. Los documentos estropeados o de contenido obsoleto se destinan al reciclado de papel.

11.2. Por otro lado, se entiende que las donaciones efectuadas a la biblioteca son altruistas y en ningún caso a cambio de una contrapartida económica o de un reconocimiento público del donante por cualquier medio. La biblioteca tampoco puede asumir el transporte de documentos de domicilios particulares a su sede. 
II.3. Los documentos finalmente incorporados permanecerán en el fondo de la biblioteca según los criterios técnicos de los bibliotecarios. En contadas ocasiones la conservación del fondo es indefinido.

II.4. La aceptación de una donación dará lugar a una misiva de agradecimiento a la persona donante.

II.5. En lo concerniente al servicio de documentos de libre disposición en él mismo, la biblioteca puede apartar de él a algunos usuarios en vista de acaparamientos exagerados (más de cuatro ejemplares diarios durante cuatro días seguidos).

Viene de la p. 151

El último punto del reglamento, acostumbra a ser una cláusula de cierre donde consta la fecha de aprobación.

\section{I. Aceptación del reglamento}

II.I. El reglamento se hará público para que los usuarios lo conozcan, y estará a disposición de quien lo pida en la biblioteca.

I I.2. La biblioteca se reserva el derecho a interpretar este reglamento a los efectos de resolver dudas y de dar más flexibilidad a los servicios.

II.3. La biblioteca puede establecer condiciones generales adicionales en el uso de sus recursos y servicios.

II.4. El uso de la biblioteca implica la aceptación de este Reglamento.

Este reglamento ha sido aprobado por el Pleno del Ayuntamiento del día (...) y publicado en el Boletín Oficial de la Provincia (...). Lugar y fecha

\section{Otros apartados}

Hemos expuesto el articulado más habitual en los reglamentos de nuestro ámbito, pero la experiencia de bibliotecas públicas de otros países también nos puede ser útil y centrar nuestra atención sobre aspectos que antes se habían obviado.

\subsection{Fotografías en la bibliote-} ca

$¿$ Debe identificarse la persona que fotografía en la biblioteca o puede hacerlo quien lo desee libremente?, ¿hay que llevar un registro de las personas que hacen fotografí- as?, ¿y si se trata de fotografiar niños en el centro? ? $^{27}$ y7

\subsection{Donaciones}

Hemos encontrado algunos reglamentos de nuestro ámbito en los que se incluye la política de donación de documentos. En nuestro ejemplo también se tiene en cuenta en el capítulo del servicio de documentos de libre disposición. Ahora bien, no sólo pueden donarse documentos, también está el caso del dinero: ¿en qué condiciones debe aceptarse?, ¿es una práctica que la biblioteca quiera incentivar?, ¿se dará algún tipo de reconocimiento a las personas que donen sumas notables?

Por otro lado, la biblioteca también puede ser donante, por ejemplo a otras instituciones bibliotecarias, a establecimientos que realizan una labor social a partir de la venta de objetos de segunda mano, etc. ${ }^{27}$.

\subsection{Ventas}

¿La biblioteca puede vender los documentos que da de baja, los duplicados o los donativos que no acepta $^{27}$ ? En EUA es una práctica común.

\subsection{Política de distribución gratuita}

Se acostumbra a ceder un espacio para la distribución de publicaciones, que en nuestro ámbito y en general corresponde a estas categorías:

-Prensa local. locales.

-Propaganda de actividades

-Folletos educativos o divulgativos normalmente de campañas institucionales.

-Información de instituciones públicas.

También recibe la petición de grupos religiosos, empresas con finalidad lucrativa (ventas de productos diversos) o políticos para hacer uso del espacio de distribución que se ofrece. ¿Qué hacer en estos ca$\operatorname{sos} ?^{27}$

\subsection{Tablón de anuncios}

Las bibliotecas suelen poseer uno para la divulgación de sus actividades. Además, también se da difusión a carteles editados por instituciones locales, en relación con actividades culturales en general, campañas institucionales, etc. Los puntos críticos de esta actividad son:

— La limitación a un espacio de exposición para determinados tipos de anuncio (y reservar los espacios preferentes para las comunicaciones de la biblioteca).

- La responsabilidad de poner o retirar del tablón. ¿A quién se debe pedir permiso?

- ¿Qué documentos tienen preferencia de exposición?

\subsection{La cesión de salas de la biblioteca}

Muchas bibliotecas tienen una sala de actos o comparten una con otras dependencias municipales. También se producen cesiones de estos espacios para actos promovidos por otras entidades o particulares; en este caso hay que estable$\operatorname{cer}^{27,35}$ :

—Quién puede hacer uso del espacio y para qué propósito ¿todo el que lo pida?, ¿para llevar a cabo cualquier tipo de reunión o debe cumplir alguna finalidad (cultural, educativa, informativa, etc.)?

- La necesidad de reservar el espacio con una antelación mínima determinada.

-En caso de peticiones múltiples ¿quién tiene prioridad?

— ¿Se podrá cobrar entrada?, ¿y vender alguna cosa?

— ¿La cesión es gratuita?, ¿hay que dejar algún depósito para usar la sala? 
- ¿A qué horas y en qué días se puede disponer de la sala?

— ¿Hay alguna limitación en el número de veces que se puede ceder la sala a una misma organización o persona?

- ¿En las reuniones particulares se podrá fumar, beber alcohol o comer?, ¿podrá utilizarse la cocina de la biblioteca para preparar el catering de la reunión?

—Responsabilidades de las personas a quien se cede la sala: disponer en el orden original el mobiliario, dejar la sala limpia, reponer los bienes que se rompan o se estropeen o, si es el caso, afrontar la reparación, mantener el orden y no interferir en las actividades de la biblioteca.

—Aforo máximo de la sala.

—La obligación de notificar la renuncia a la sala cuanto antes mejor.

- La reserva de la biblioteca para cancelar o modificar una reserva bajo determinadas circunstancias.

\subsection{Exposiciones}

Normalmente las bibliotecas públicas con espacio de exposición lo ceden sin establecer muchos requisitos, el hecho de ser autor local ya es condición suficiente. Ahora bien, centros más grandes acostumbran a ser más exigentes y pueden disponer incluso de un comité de selección:

—Composición del comité de selección.

-Presentación de peticiones con reproducciones de la obra que se quiere exponer en la sala en un formato concreto (diapositivas de $25 \mathrm{~mm}$ o fotografías en color). La obligación (o no) de devolver el material de presentación de la obra que acompaña la solicitud.

- Criterios valorables por el comité de selección. Aquí reprodu-

El profesional de la información está abierto a todos

los bibliotecarios, documentalistas y otros profesionales de la información, así como a las empresas y organizaciones del sector para que puedan exponer sus noticias, productos, servicios, experiencias y opiniones.

Dirigir todas las colaboraciones para publicar a:

El profesional de la información

Apartado 32.280

08080 Barcelona

epi@elprofesionaldelainformacion.com

cimos los de la Wallingford Public Library $^{27}$ : la habilidad artística, el interés local de la exposición, la adecuación a los usuarios de la biblioteca, la promoción de jóvenes talentos y la exposición de medios artísticos variados.

- ¿A quién corresponde contratar un seguro?

- Metros cuadrados de exposición ofrecidos y número de piezas que pueden exponerse razonablemente. Disponibilidad de paneles, urnas o pies de exposición.

- ¿Quién debe montar y desmontar la exposición? El horario en el que estas operaciones se pueden llevar a cabo (sin estorbar la actividad principal de la biblioteca).

-Duración máxima de una exposición.

- Todos los cuadros deben estar enmarcados y preparados para ser colgados por un sistema de fijación determinado (normalmente carril con hilo de pescar). ¿Pueden agujerearse las paredes de la biblioteca?

— La necesidad de etiquetar cada pieza con autor, título y/o técnica y dimensiones. ¿Cómo se fijan a la pared?

- La obligación o no de disponer de vigilancia en la sala de exposición.

—El horario de exposición establecido.
—La posibilidad de inaugurar con un aperitivo, y ¿quién debe organizarlo y sufragarlo?

-El expositor debe proporcionar una lista con el precio de cada obra y una dirección con el fin de que los interesados en adquirirlas se pongan en contacto directamente con él.

- La reserva de cancelar una exposición.

- ¿La publicidad que se distribuya sobre la exposición debe pasar antes por el comité de selección?

- ¿El expositor debe ceder alguna pieza a la biblioteca a cambio de la cesión de la sala?

\subsection{Voluntariado}

En EUA y Canadá es muy común el uso de voluntarios para realizar determinadas labores. A veces existe un comité de selección que valora currículos y disponibilidad de los candidatos, asigna tareas y también se establecen tanto sus obligaciones (cumplir los compromisos adquiridos) como los de la biblioteca (supervisar la tarea, ofrecer formación específica a los voluntarios, etc.).

\section{Bibliografía}

1. "Biblioteca Pública Julià Cutillé de Llagostera: normativa". En: Butlletí Oficial de la Província de Girona, 2003, n. 7, pp. 26-28.

2. "Modificació de l'ordenança reguladora de la utilització de la biblioteca de Sant Agustí". En: Butlletí Oficial de la Província de Lleida, 2001, n. 14, annex, pp. 77-78. 
3. "Normativa d'ús de les biblioteques: Consorci de Biblioteques de Barcelona". En: Butlletí Oficial de la Província de Barcelona, 2004, n. 173, pp. 86-87.

4. Normativa d'ús del servei de préstec de les biblioteques de la Xarxa de la província. Consultado en: 10-12-04.

http://www.diba.es/biblioteques/guia/serveis/pre stec.asp

5. "Normativa de la Biblioteca Milà i Fontanals de Begues". En: Butlletí Oficial de la Província de Barcelona, 2000, n. 94, pp. 83-84.

6. "Normativa de la Biblioteca Pública Municipal de Cambrils". En: Butlletí Oficial de la Província de Tarragona, 2001, n. 58, pp. 17-19.

7. "Normativa de la Biblioteca Pública Municipal de Constantí". En: Butlletí Oficial de la Província de Tarragona, 2004, n. 196, pp. 7-11.

8. "Normativa per a l'ús de les biblioteques i sales de lectura de Mollet del Vallès". En: Butlletí Oficial de la Província de Barcelona, 2004, n. 61, pp. 69-70.

9. "Normativa reguladora de la utilització de la biblioteca comarcal de Móra d'Ebre". En: Butlletí Oficial de la Província de Tarragona, 2001, n. 67, pp. 156-158.

10. "Normes d'ús de la Biblioteca de Santa Margarida i els Monjos”. En: Butlletí Oficial de la Província de Barcelona, 2003, n. 290, pp. 53-54.

11. "Normes d'ús de les biblioteques [de Sant Boi de Llobregat]". En: Butlletí Oficial de la Província de Barcelona, 2004, n. 12, annex, pp. 69-71.

12. "Normes d'ús de les biblioteques [de Sant Esteve Sesrovires]". En: Butlletí Oficial de la Província de Barcelona, 2004, n. 175, pp. 80-81.

13. "Normes reguladores del funcionament de la Biblioteca Comarcal Jaume Vila [Mollerussa]". En: Butlletí Oficial de la Província de Lleida, 2002, n. 56, pp. 38-41.

14. "Reglament d'ordre intern de la Biblioteca Comarcal "Josep Finestres" de Cervera". En:
Butlletí Oficial de la Província de Lleida, 2001, n. 84 , pp. 7-8.

15. "Reglament d'ús de la Biblioteca municipal Mossèn Cinto Verdaguer". En: Butlletí Oficial de la Província de Barcelona, 2004, n. 266, pp. 115-116.

16. "Reglament de la Biblioteca Aigüestoses". En: Butlletí Oficial de la Província de Barcelona, 2004, n. 110, pp. 43-44.

17. "Reglament de la Biblioteca Ferran Soldevilla [de Santa Maria de Palautordera]". En: Butlletí Oficial de la Província de Barcelona, 2001, n. 22, pp. 97-100.

18. "[Reglament de la Biblioteca municipal de Palafrugell]". En: Butlletí Oficial de la Provín cia de Girona, 2002, n. 16, pp. 19-21.

19. "Reglament de la Biblioteca municipal de Sant Quirze del Vallès". En: Butlletí Oficial de la Província de Barcelona, 2002, n. 112, pp. 89-91.

20. "Reglament de la Biblioteca Popular d'Ulldecona". En: Butlletí Oficial de la Província de Tarragona, 2004, n. 18, pp. 20-22.

21. "Reglament de la Biblioteca Pública Municipal Rafael Vilà Barnils d'Arbúcies". En: Butlletí Oficial de la Província de Girona, 2004, n. 232, pp. 16-18.

22. "Reglament de Règim interior de les instal-lacions de la Biblioteca Municipal [de Piera]". En: Butlletí Oficial de la Província de Barcelona, 2000, n. 286, pp. 52-53.

23. "Reglament de règim intern de la Biblioteca Pública de Banyoles". En: Butlletí Oficial de la Província de Girona, 2002, n. 198, pp. 16-18.

24. "Reglament de Règim intern de la Biblioteca Pública Municipal de Salou". En: Butlletí Oficial de la Província de Tarragona, 2002, n. 244, pp. 20-22.

25. "Reglament del servei de préstec de la Xarxa Municipal de Biblioteques de L'Hospitalet". En: Butlletí Oficial de la Província de Barcelona, 2003, n. 242, pp. 85-87.

\section{IweTel}

Es un foro electrónico de debate, puesto en marcha por EPI - EI profesional de la información, sobre información, documentación, biblioteconomía y sus tecnologías.

En la actualidad cuenta con más de 5.200 suscriptores.

Para suscribirse a IweTel hay que enviar a la dirección:

listserv@listserv.rediris.es

un mensaje en cuyo cuerpo figure:

subscribe iwetel Nombre Apellido

Se puede participar en IweTel remitiendo los mensajes a: iwetel@listserv.rediris.es

Más información en:

http://www.rediris.es/list/info/iwetel.html
26. "Reglament per a la regulació de la Biblioteca Pública Municipal Berenguer de Bellvís". En: Butlletí Oficial de la Província de Lleida, 2002, n. 65, pp. 19-21.

27. Wallingford Public Library, about the $l i$ brary. Consultado en: 10-12-04.

http://www.wallingford.lioninc.org/aboutlibrary. htm

28. Rules of behavior: Oak Park Public Library. Consultado en: 10-12-04.

http://www.oppl.org/index.htm

29. Rules governing the use of the library. Consultado en: 10-12-04.

http://elwood.suffolk.lib.ny.us/pdf/libraryrules.pdf

30. Patron code of behavior: Taylor County Public Library. Consultado en: 10-12-04.

http://taylor.clark.lib.wv.us/Patron\%20Code\%20 of\%20Behavior.pdf

31. Roswell Public Library rules. Consultado en: 10-12-04.

http://www.roswellpubliclibrary.org/ServPol/Rul es.htm

32. Rules governing the use of the library: Texarkana Public Library. Consultado en: 10-12-04.

http://www.txar-publib.org/TEXARKANA\%2OP UBLIC\%2OLIBRARY.htm

33. Molalla Public Library code of conduct. Consultado en: 10-12-04.

http://www.molalla.lib.or.us/page6.html

34. Rules governing the use of the Saint Paul Public Library. Consultado en: 10-12-04. http://www.sppl.org/userguide.cfm?id=41

35. Library services and polices: the Lane libraries. Consultado en: 10-12-04. http://www.lanepl.org/services.html

36. Code of conduct: City of Louisville Public Library. Consultado en: 10-12-04. http://www.ci.louisville.co.us/library/cond.asp

37. Code of conduct in the library: Urbandale Public Library. Consultado en: 10-12-04. http://www.urbandalelibrary.org/index.php? mod ule $=$ htmlpage $\&$ func $=$ display \& pid $=24$

38. Policy on patron guidelines: Cleveland Public Library. Consultado en: 10-12-04. http://www.cpl.org/Locations.asp? FormMode $=P$ atrons

39. Library polices: Liverpool Public Library patron code of conduct. Consultado en: 10-12-04.

http://www.lpl.org/AboutLPL/Policies/PatronCo nduct.html

40. Kelly, D. B. "Problem patrons: all shapes and sizes". En: The reference librarian, 2002, n. 75-76, pp. 3-10.

De hecho el número 75-76 de The reference librarian es un monográfico sobre usuarios conflictivos: "Helping the difficult library patron: new approaches to examining and resolving a long-standing and ongoing problem".

$M^{a}$ Rosa López Llebot, Biblioteca Pública Torras i Bages de Vilafranca del Penedès. info@zonaele.com 